\title{
New tools, methods needed to replace methyl bromide
}

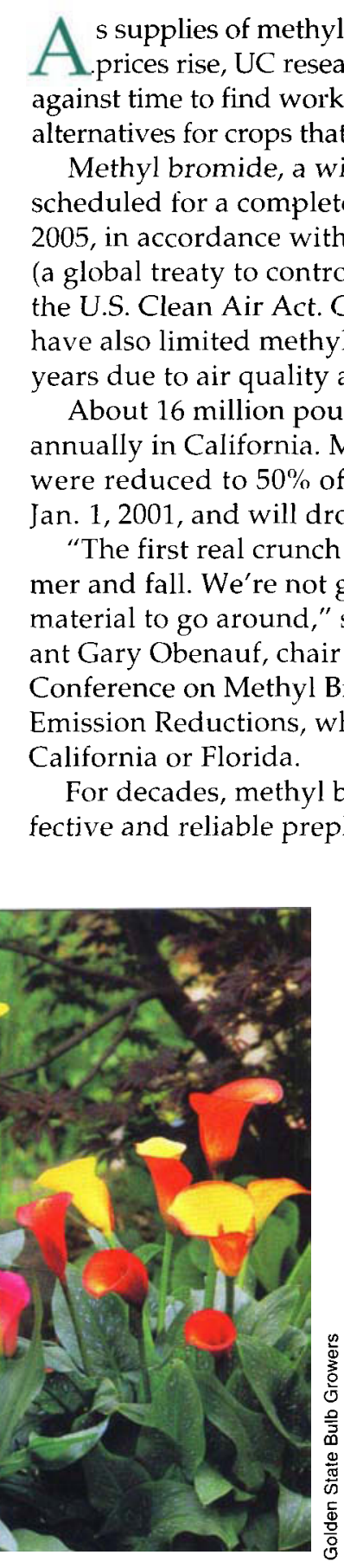

1. supplies of methyl bromide dwindle and prices rise, UC researchers have been racing find workable, economically viable ternatives for crops that will be affected.

Methyl bromide, a widely used fumigant, is scheduled for a complete phase-out by Jan. 1, 2005, in accordance with the Montreal Protocol (a global treaty to control ozone depletion) and the U.S. Clean Air Act. California regulators have also limited methyl bromide's use in recent ity and health concerns.

About 16 million pounds have been applied annually in California. Methyl bromide supplies were reduced to $50 \%$ of the 1991 baseline on an. 1, 2001, and will drop by 75\% in 2003 .

"The first real crunch will come in late summer and fall. We're not going to have enough material to go around," says agricultural consultant Gary Obenauf, chair of the International Conference on Methyl Bromide Alternatives and Emission Reductions, which is held annually in alifornia or Florida.

For decades, methyl bromide has been an efnematodes, weeds and

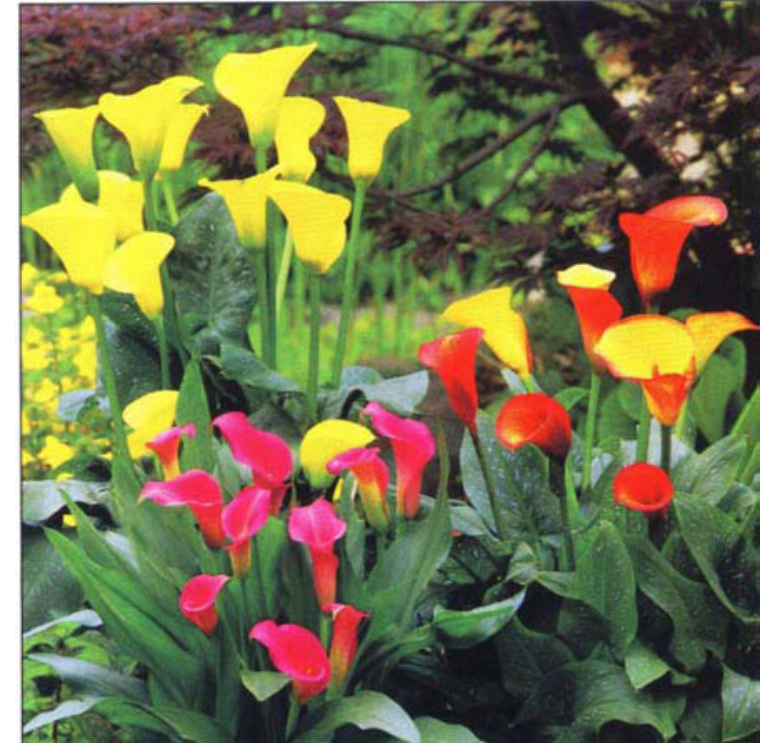

Researchers are testing solarization in combination with soil amendments as an alternative for methyl bromide in fields planted to callas, like these near Monterey. pathogens, as well as a required postharvest treatment for numerous crop exports and imports. An exemption is currently in place for preshipment and quarantine uses, but even so, the fumigant will be more difficult and expensive to use in the future.

The first drop in supplies (25\% in 1999) was not a major problem for California growers because some were able to substitute alternative chemicals such as 1,3-D (Telone) plus chloropicrin,

Obenauf says. However, California places major restrictions on $1,3-\mathrm{D}$, making it a less-thanoptimal replacement chemical (see p. 12).

Growers will experience "real shortages for the first time" during the 2001 season, Obenauf predicts. "And prices have gone up significantly."
Scientists around the nation and world have been racing to develop methyl bromide alternatives since the early 1990s. A multitude of strategies are under investigation, including new chemical treatments, soil solarization, fieldflooding, resistant rootstocks, compost, organic cultivation, cover crops and bacterial inoculants. "We're making really good progress, better than we thought was possible," Obenauf says.

A number of global, federal and state agencies have supported research, as have the commodities and industries affected. In 1998, the California Legislature passed a special allocation of \$1 million to promote alternatives to methyl bromide. The funds are administered by the UC Sustainable Agriculture Research and Education Program (SAREP); researchers are now in their third year of projects.

"We're pleased that the projects we've funded are employing biologically based solutions such as microorganisms, farming rotations that suppress soil-borne pathogens, the use of clean nursery material and resistant rootstocks," UC SAREP director Sean Swezey says.

\section{SAREP-funded research}

Strawberries are the specialty crop with perhaps the most to lose from the methyl bromide phase-out. About 1.4 billion pounds are grown in California each year, with more than 26,000 harvested acres worth nearly $\$ 800$ million. The vast majority of strawberry acreage has been treated with methyl bromide for many years.

SAREP allocated $\$ 160,000$ of the state funds to a 3-year, on-farm demonstration project in the Monterey Bay region examining biointensive production alternatives to methyl bromide in strawberries. The project is called BASIS (Biological Agriculture Systems in Strawberries).

The following summaries of six SAREPfunded research projects are based on progress reports submitted in mid-2000

(www.sarep.ucdavis.edu/mebralt/).

Containerized strawberry transplants. More than 900 million strawberry transplants are produced in California nurseries each year, with methyl bromide (plus chloropicrin) applied to guarantee that they are nematode- and disease-free. UC Davis pomologist Kirk Larson is exploring plug plants, which are used successfully in other strawberry-growing regions but not California. Research into runner plant age, con- 
tainer sizes and high-elevation plant conditioning will be conducted during the 20012002 growing season.

Biofumigation for coastal ornamentals. California's coastal areas are highly productive for ornamental crops such as glasshouse foliage and flowers and field-grown cut flowers, bulbs and greens. UC Davis plant pathologist James MacDonald is determining the efficacy of biofumigation - soil solarization enhanced by organic soil amendments - to control soilborne fungi, bacteria and weeds in field-grown ornamentals. Experimental amendments included broccoli, blood meal, composted chicken manure, corn gluten meal, acetic acid and aqueous ammonia. Broccoli residues incorporated into soil during solarization achieved significant reductions in weed populations.

Postharvest fumigation of strawberries. California strawberries are fumigated with methyl bromide prior to export to important markets in Japan and Australia. UC Davis pomologist Elizabeth Mitcham is experimenting with natural volatile compounds of fruit, alone and in combination with controlled atmosphere treatments, for efficacy against various insect pests. Treatments with naturally occurring acetaldehyde and carbon dioxide, which would require virtually no modifications to existing fumigation chambers, have been effective against some insects and can actually enhance the flavor of fruits.

Nematode-resistant grape rootstocks. Methyl bromide is commonly used as a preplant fumigant for vineyard establishment in San Joaquin and Central Coast valleys. UC Davis nematologist Howard Ferris has screened about 45 rootstocks for resistance to two important nematodes, and found six with resistance to both.

Rhizosphere bacteria and strawberries. Bacteria isolated from the soil around roots (rhizosphere) of fumigated strawberries has been demonstrated to promote strawberry growth in greenhouses. UC Davis plant pathologist John Duniway is studying how inoculations with several types of Pseudomonas bacteria can contribute to root health, growth and yield of strawberries in the field, with and without soil fumigation treatments.

Replant disorder of Prunus spp. Greg Browne of USDA-Agricultural Research Service/UC Davis plant pathology department is studying replant disorder, which causes poor and irregular tree growth and delayed crop production. Its causes can include nematodes, root fungus or Phytophthora. Data is being gathered on the impacts of fallowing, cover crops and cropping patterns, to help growers assess risks and optimize replanting schedules.

\section{Other projects}

Additional projects involving methyl bromide alternatives are under way in many corners of the University. Past and ongoing projects have included methyl iodide as a replacement fumigant; methods to destroy old plant roots; ultraviolet treatments to kill foodspoiling microorganisms; soil solarization in San Joaquin Valley strawberries; composted green waste, pine bark and pecan shells to suppress weeds in nursery container soils; changes in irrigation practices to control oak root fungus; and soil solarization to sterilize nursery pots.

The UC Statewide Integrated Pest Management (IPM) Program has also funded several projects, including a study of Verticilium wilt in strawberry and the augmentation of a database of thermal death dosages for soil solarazation.

The California Strawberry Commission has been spending more than $\$ 500,000$ annually on methyl bromide alternatives research since 1993 , with $16 \mathrm{UC}$ and USDA researchers receiving funding. Other commodity boards are researching alternatives to varying degrees.

Despite all the energy devoted to the problem, finding suitable alternatives for all the myriad uses of methyl bromide will continue to be a challenge. "It is unlikely that we will find a single 'magic bullet' replacement chemical," UC SAREP associate director Janet Broome says.

"Researchers and growers for each crop need to be rethinking their whole farming systems to survive without this tool."

- Janet Byron
USDA plant pathologist Carolee Bull, principal investigator for the Biological Agriculture Systems in Strawberries (BASIS) project, checks strawberries in a test field with Ron Koda of the California Strawberry Board. BASIS is one of several projects funded by UC SAREP to promote alternatives to methyl bromide for strawberries. 